\title{
Cystic fibrosis transmembrane conductance regulator expression in human spinal and sympathetic ganglia
}

\author{
Na Niu', Jie Zhang ${ }^{2}$, Yong Guo ${ }^{1}$, Chunzhang Yang ${ }^{3}$ and Jiang Gu ${ }^{1,4}$
}

Cystic fibrosis transmembrane conductance regulator (CFTR) is a chloride channel protein, and mutations of its gene cause cystic fibrosis. CFTR is known to be expressed in epithelial cells of the respiratory, digestive and reproductive tracts. It is also present in rat neurons and heart ganglion cells. In humans, it is expressed in the hypothalamus, but has not been identified in other parts of the human nervous system. In this study, immunohistochemistry, double-staining immunofluorescence, in situ hybridization, nested reverse transcription-PCR and relative quantification of real-time PCR analysis were performed on spinal and sympathetic ganglia from seven human autopsies with no known nervous system disease. CFTR protein was expressed in most ganglion cells with no obvious difference in the amounts of mRNA transcript in ganglia of different sites. We conclude that CFTR protein and its mRNA were extensively expressed at relatively constant levels in human spinal and sympathetic ganglion cells, and may be important in physiological and pathological conditions. Moreover, CFTR in ganglia may be associated with pathophysiological changes seen in cystic fibrosis. Laboratory Investigation (2009) 89, 636-644; doi:10.1038/labinvest.2009.28; published online 30 March 2009

KEYWORDS: cystic fibrosis; cystic fibrosis transmembrane conductance regulator; ganglion; ganglion cells; human

Mutations of cystic fibrosis transmembrane conductance regulator (CFTR) gene is the cause of cystic fibrosis (CF), which is the most common autosomal recessive genetic disorder in Caucasian population, with an occurrence of 1 in 2000 live births. It affects a number of organs and is characterized by progressive bronchiectatic lung disease, pancreatic insufficiency, chronic sinusitis and infertility in men. ${ }^{1,2}$ In addition, electronic abnormalities of peripheral nerve ${ }^{3}$ and derangement of autonomic responses ${ }^{4-13}$ were detected in patients with $\mathrm{CF}$, indicating that the peripheral ganglia may be involved in the pathophysiological changes of CF.

Cystic fibrosis transmembrane conductance regulator is known to be present in mucous membrane and glandular epithelium of the respiratory, digestive and reproductive tracts. ${ }^{14-16}$ As an adenosine $3^{\prime}: 5^{\prime}$ cyclic monophosphate-dependent chloride channel, this protein creates an efflux channel in the cell membrane, allowing chloride, anions such as glutathione to cross. ${ }^{17}$ It is also involved in acidifying organelles and regulating membrane vesicle transport and confluence. ${ }^{18-23}$ In addition to expression in epithelial cells, CFTR is also found in neurons of rat brain and human hypothalamus. ${ }^{24,25}$ However, the functional significance of CFTR in nonepithelial cells remains unknown.
As CFTR has been found in epithelial and nonepithelial cells, and in view of the abnormalities of peripheral nervous system of CF noted above, we hypothesized that CFTR may be present in human ganglion cells and attempted to verify this hypothesis with qualitative and quantitative methods.

\section{MATERIALS AND METHODS Human Spinal and Sympathetic Ganglia}

Bilateral $C_{1}$ (first cervical vertebrae) to $C_{3}$ (third cervical vertebrae) spinal ganglia, stellate ganglion, $\mathrm{T}_{2}$ to $\mathrm{T}_{10}$ sympathetic ganglia, celiac ganglia and inferior mesenteric ganglia were obtained from seven human subjects without known disease of the nervous system at autopsy. In each case appropriate consent for autopsy was obtained. General states of these seven human subjects are shown in Table 1.

$\mathrm{C}_{1}$ to $\mathrm{C}_{3}$ spinal ganglia, spindle-shaped bulges, are located in the posterior spinal root near the confluence of the anterior root, and lie along the vertebral column by the spine. The sympathetic trunk travels downward from the skull, lateral to the vertebral bodies. It consists of ganglia and sympathetic fibers between them. Based on their locations, ganglia in sympathetic trunk are divided into three different

\footnotetext{
${ }^{1}$ Department of Pathology, School of Basic Medical Sciences, Peking University, Beijing, China; ${ }^{2}$ Department of Human Anatomy, Weifang Medical University, Shangdong Province, China; ${ }^{3}$ Neuroscience Research Institute, Peking University, Beijing, China and ${ }^{4}$ Department of Pathology, Shantou University Medical College, Shantou, China Correspondence: Professor J Gu, MD, PhD, Department of Pathology, School of Basic Medical Sciences, Peking University, Beijing 100191 and Department of Pathology, Shantou University Medical College, Shantou 515041, China.
}

E-mail: jianggudrive@gmail.com

Received 9 October 2008; revised 8 March 2009; accepted 9 March 2009 
Table 1 General information of seven studied subjects

\begin{tabular}{|c|c|c|c|c|c|c|c|}
\hline Number & 1 & 2 & 3 & 4 & 5 & 6 & 7 \\
\hline Age (years) & 0.5 & 37 & 24 & 27 & 14 & 42 & 4 \\
\hline Gender & $\mathrm{F}$ & $M$ & $M$ & $M$ & $F$ & $M$ & $F$ \\
\hline Cause of death & Pneumonia & $\begin{array}{l}\text { Acute pancreatitis, } \\
\text { acute abdomen }\end{array}$ & $\begin{array}{l}\text { Trauma, liver } \\
\text { rupture }\end{array}$ & $\begin{array}{l}\text { Disruption of } \\
\text { hemangioma }\end{array}$ & Accident & $\begin{array}{l}\text { Myocardial } \\
\text { infarction }\end{array}$ & $\begin{array}{l}\text { Inhalation of foreign } \\
\text { object }\end{array}$ \\
\hline Storage temperature & Room temperature & $-20^{\circ} \mathrm{C}$ & $-20^{\circ} \mathrm{C}$ & $-20^{\circ} \mathrm{C}$ & $-20^{\circ} \mathrm{C}$ & $-20^{\circ} \mathrm{C}$ & Room temperature \\
\hline How long the tissues & 2 & 14 & 10 & 7.5 & 17 & 4 & 3.5 \\
\hline $\begin{array}{l}\text { were collected after } \\
\text { death (h) }\end{array}$ & & & & & & & \\
\hline
\end{tabular}

M, male; F, female.

groups: the cervical, thoracic and lumbar ganglia. ${ }^{26}$ The cervical ganglia consist of the superior, the middle and the inferior cervical ganglia from top to bottom. The middle cervical ganglia were not obtained in three of these seven subjects. The inferior cervical ganglion was fused with the first thoracic ganglion forming the stellate ganglion in all the subjects. It was located at the level of $\mathrm{C}_{7}$ (seventh cervical vertebrae), anterior to the transverse process of $\mathrm{C}_{7}$, posterior to the neck of the first rib and below the subclavian artery. The postganglionic fibers from stellate ganglion innervate the lung and the heart. The stellate ganglion of cervical group and $\mathrm{T}_{2}$ (2nd thoracic vertebrae) to $\mathrm{T}_{10}$ (10th thoracic vertebrae) ganglia of thoracic group in both sides were taken.

Celiac ganglia and inferior mesenteric ganglia belong to the sympathetic ganglia and connect with the sympathetic trunk. Celiac ganglia were two large irregularly shaped masses of nerve tissue in the upper abdomen, and they innervate most of the digestive tract. They were placed on either side of the midline in front of the crura of the diaphragm, close to the adrenal glands, and the right celiac ganglion was placed behind the inferior vena cava. The inferior mesenteric ganglion was located near where the inferior mesenteric artery branches from the abdominal aorta.

Stomach and ileum samples, known for CFTR expression, were also taken as the positive control. ${ }^{14}$

After dissection, ganglia from one side were immediately snap-frozen in liquid nitrogen and then stored at $-80^{\circ} \mathrm{C}$, and the corresponding counterlateral ganglia were fixed in $4 \%$ paraformaldehyde and embedded in paraffin.

\section{Immunohistochemistry}

Immunohistochemistry (IHC) was performed on consecutive paraffin-embedded tissue sections to demonstrate CFTR protein expression in human ganglia. After deparaffinization in xylene and rehydrating in gradient ethanols, sections were incubated in 70\% ammonia-ethanol at room temperature for $30 \mathrm{~min}$ to remove formalin deposition. After being washed in $0.01 \mathrm{M}$ phosphate-buffered saline (PBS), sections were heated in sodium citrate buffer $(\mathrm{pH} 6.0)$ at $96^{\circ} \mathrm{C}$ for $15 \mathrm{~min}$ to retrieve antigen, ${ }^{27}$ and then cooled to room temperature. Hydrogen peroxide (3\%) incubation for $30 \mathrm{~min}$ at room temperature was used to block the endogenous peroxidase activity and then sections were washed with $0.01 \mathrm{M}$ PBS for 2 min. Primary mouse anti-human monoclonal antibodies to neurofilament (NF, 1:100; Dako, Copenhagen, Denmark) and CFTR (directed against the second nucleotide-binding domain near the C terminus) (1:100; Lab Vision, Fremont, CA, USA), polyclonal goat anti-human antibody to CFTR (directed against the 20 peptides near the $\mathrm{N}$ terminus) (1:100; Santa Cruz, Santa Cruz, CA, USA) were used to identify ganglion cells and CFTR-positive cells, respectively. Horseradish-peroxidase-conjugated anti-mouse/rabbit IgG (PV9000 immunohistochemistry kit; Zymed Laboratories, San Francisco, CA, USA) and horseradish-peroxidaseconjugated anti-goat IgG (1:1000; Jackson, West Grove, PA, USA) were used as the secondary antibody. 3-Amino-9-ethylcarbazole (AEC) or 3,3'-diaminobenzidine (DAB) was used for coloration. Mucous layer of stomach was used as the positive control where the epithelial cells are known to contain CFTR. PBS substituting primary antibodies was used as the negative control.

The antigen neutralization technique was used to verify antibody specificity to CFTR. ${ }^{28}$ Graduated amounts of CFTR protein (a peptide fragment near the $\mathrm{N}$ terminus) $(20 \mu \mathrm{g} / \mathrm{ml}$; Santa Cruz) were incubated with the CFTR antibody solution (dilution 1:100) and the solution mixtures were added to the slides. The specificity of the antibody and immunostaining can be established if the positive immunostaining decreases as the protein antigen concentration increases, leading to eventual disappearance of the positive immunostaining on the slides.

A destain and restain technique ${ }^{29}$ was also used to confirm CFTR location and distribution. After coloration of CFTR antigen, photos were taken, then the sections were heated at $96^{\circ} \mathrm{C}$ in sodium citrate buffer ( $\mathrm{pH}$ 6.0) for $10 \mathrm{~min}$ again to discolor and get rid of antigen-antibody complex. Then the new primary antibody to NF, specific for neurons, was added 
and incubated at $4^{\circ} \mathrm{C}$ overnight. The subsequent procedures were the same with IHC described above.

\section{Double-Staining Immunofluorescence}

To confirm the identity of CFTR-positive cells, doublestaining immunofluorescence microscopy was performed. A total of $4 \%$ paraformaldehyde-fixed paraffin-embedded sections of ganglia $(4 \mu \mathrm{m})$ were deparaffinized, rehydrated and antigen was retrieved as described in the IHC procedure. Then the slides were soaked in $0.2 \%(\mathrm{v} / \mathrm{v})$ Triton X-100/PBS for $15 \mathrm{~min}$ at room temperature. After blocking with $10 \%(\mathrm{v} / \mathrm{v})$ goat serum/PBS for $60 \mathrm{~min}$ at room temperature, sections were incubated overnight with polyclonal rabbit anti-human NF heavy polypeptide antibody (1:100; Bioss, Beijing, China) and monoclonal mouse anti-human CFTR antibody (1:100; Lab Vision) at $4{ }^{\circ} \mathrm{C}$ and washed twice with $0.2 \%(\mathrm{v} / \mathrm{v})$ Triton $\mathrm{X}-100 / \mathrm{PBS}$ for $10 \mathrm{~min}$ each, and then incubated away from light with fluorescein isothiocyanate (FITC)-conjugated goat anti-rabbit IgG and rhodamine (TRITC)-conjugated goat anti-mouse IgG (1:100; Jackson) at $37^{\circ} \mathrm{C}$ for $30 \mathrm{~min}$. Hoechst 33342 (1:1000; Sigma-Aldrich, St Louis, MO, USA) was used to color the nucleus. Blank controls including replacement of primary or secondary antibodies or both with PBS were used. After mounting with glycerol/PBS (9:1), slides were observed with a BX51 microscopic (Olympus, Shinjuku, Tokyo, Japan).

\section{RNA Extraction and Nested RT-PCR}

Nested reverse transcription (RT)-PCR was used to assay CFTR mRNA expression in human ganglia. Mucous layer of ileum was used as a positive control. The total RNA was isolated from frozen ganglion and ileum mucosa tissues using TRIzol reagent (Invitrogen, Carlsbad, CA, USA) according to the manufacturer's protocol. According to CFTR mRNA sequence from GenBank (accession no. NM_000492.), one specific primer (5'-CAGGAAACCAAGTCCACAG-3') was designed for RT, and two pairs of specific primers (external: 5'-GCCCTTCGGCGATGTT-3', 5'-CAGGAAACCAAGTCCA CAG-3'; internal: 5'-AGGAGGAACGCTCTATCG-3' ${ }^{\prime}$, '-GCA GACGCCTGTAACAAC- $3^{\prime}$ ) were designed for nested PCR. $\beta$-Actin (primers: sense, $5^{\prime}$-TAAAGACCTCTATGCCAACA CAG- ${ }^{\prime}$; antisense, $5^{\prime}$-CACGATGGAGGGGCCGGACTCA TC- $3^{\prime}$ ) were amplified as an endogenous reference. The final amplifying segment of CFTR was $328 \mathrm{bp}$ long and spanned two introns of CFTR gene. Five micrograms of total RNA extracted from tissues was reverse transcribed with random primer or specific primer using SuperScript III Reverse Transcriptase (Invitrogen) according to the manufacturer's instructions. The reaction was performed at $55^{\circ} \mathrm{C}$ for $60 \mathrm{~min}$. Nested PCR was carried out with HotStart Taq DNA Polymerase (GenStar Biosolutions, Beijing, China). The first amplification of nested PCR with the external primers began with incubation at $95^{\circ} \mathrm{C}$ for $5 \mathrm{~min}$, proceeded for 40 cycles at $94^{\circ} \mathrm{C}$ for $1 \mathrm{~min}, 52^{\circ} \mathrm{C}$ for $30 \mathrm{~s}$ and $72^{\circ} \mathrm{C}$ for $30 \mathrm{~s}$. The final cycle was followed by an extension of $10 \mathrm{~min}$ at $72^{\circ} \mathrm{C}$. The second amplification with the internal primers was performed in an identical manner to the first amplification but at a different annealing temperature of $54^{\circ} \mathrm{C}$.

\section{Relative Quantification of Real-Time PCR}

To check the levels of CFTR transcripts in ganglion cells, relative quantification of real-time PCR (qPCR) was performed in triplicates with SYBR Premix Ex Taq (TaKaRa, Dalian, China) containing SYBR Green I, TaKaRa Ex Taq, dNTP mixture and $\mathrm{Mg}^{2+}$. Primers for CFTR amplification/ quantification were the same as the external primers used for nested RT-PCR. Human neurofilament medium peptide (NF-M) was amplified and quantified with primers (designed according to human NF-M mRNA, NM_005382.2): sense, 5'-TATGCACCAGGCCGAAGAGT-3'; antisense, 5'-GGAGCT TCCACCTTGGGTTT- $3^{\prime}$. $\quad \beta$-Actin was used for normalization. The reaction mixture contained $25 \mu \mathrm{l}$ of $2 \times$ SYBR Premix Ex Taq, $1 \mu \mathrm{l}$ of forward and reverse primers $(10 \mu \mathrm{M})$, $18 \mu \mathrm{l}$ of di-ionized water. Real-time PCR reaction master mix was dispensed in appropriate volumes into each well of a PCR plate and finally $5 \mu \mathrm{l}$ of cDNA was added as a PCR template to the individual PCR wells containing the master mix for a total reaction volume of $50 \mu$ l. Blank controls with the template omitted were used. Real-time PCR was performed using the ABI PRISM 7500 Real-Time PCR system (Applied Biosystems, Foster City, CA, USA), using the following protocol: a denaturation cycle $\left(95^{\circ} \mathrm{C}\right.$ for $\left.10 \mathrm{~s}\right)$; amplification and quantification cycles repeated 40 times $\left(95^{\circ} \mathrm{C}\right.$ for $5 \mathrm{~s}, 55^{\circ} \mathrm{C}$ for $20 \mathrm{~s}, 72^{\circ} \mathrm{C}$ for $34 \mathrm{~s}$ with a single fluorescence measurement) and a dissociation stage.

\section{Sequence Analysis and cRNA Probe Preparation}

To analyze the sequence and generate the cRNA probe for in situ hybridization (ISH), DNA bands of $328 \mathrm{bp}$ of second amplification of nested PCR were excised from 2\% agarose gels and purified with Universal DNA purification kit (Tiangen Biotech, Beijing, China), and then subcloned into the pGM-T vector containing SalI and NcoI fragment sites. The vector was used to transfect the XLl-Blue Escherichia coli to amplify. The E. coli were grown on Luria broth agar plates containing ampicillin $(100 \mu \mathrm{g} / \mathrm{ml})$ and X-gal $(80 \mu \mathrm{g} / \mathrm{ml})$. Then the plasmid was collected from positive colonies obtained through blue-white selection, and purified with a Plasmid Mini Kit I (Omega Bio-Tek, Norcross, GA, USA) according to the manufacturer's protocol and the sequence was analyzed. NcoI restriction enzyme was used to linearize the plasmid, and T7 RNA polymerase was used to transcribe the cRNA probe in vitro. Then the cRNA probe was labeled with Digoxigenin RNA Labeling Mix (Roche Molecular Biochemicals, Mannheim, Germany).

\section{In Situ Hybridization}

In situ hybridization was performed to detect CFTR mRNA in human ganglia with the specific CFTR probes prepared as described above. Sections used were consecutive to the ones 
used in IHC. Diethyl pyrocarbonate-treated water was used to prepare all solutions used before hybridization incubation. Briefly, after deparaffinization and rehydration, sections were heated at $96^{\circ} \mathrm{C}$ in sodium citrate buffer ( $\mathrm{pH} \mathrm{6.0)}$ ) for $15 \mathrm{~min}$ with microwave ${ }^{27}$ and then incubated with hybridization cocktail containing digoxigenin-labeled CFTR probe at $45^{\circ} \mathrm{C}$ for $20 \mathrm{~h}$. Then the sections were washed in $2 \times$ SSC containing $50 \%$ formamide one time for $15 \mathrm{~min}, 2 \times$ SSC two times for $15 \mathrm{~min}$ each. After blocking with normal horse serum at room temperature for $60 \mathrm{~min}$, sections were incubated with Anti-digoxigenin-AP (1:500; Roche Diagnostics, Mannheim, Germany) for $1 \mathrm{~h}$, and colorized with nitroblue tetrazolium/5-bromo-4-choloro-3-indolyl phosphate (NBT/BCIP) (Promega Corp., Madison, WI, USA), showing a purple or amethyst signal. Methyl green was used as the counterstain. Stomach mucous layer was used as the positive control. An unrelated probe of similar nucleotide content and length was used as the negative control.

\section{Statistical Analysis}

Immunohistochemistry sections of $\mathrm{C}_{1}$ spinal ganglia, stellate ganglia, $T_{5}$ sympathetic ganglia, celiac ganglia and inferior mesenteric ganglia were selected as representatives for statistical analysis. Five random fields of each tissue section stained for CFTR by IHC were photographed under a light microscope at $\times 400$ magnification (BX51; Olympus). Total NF- and CFTR-positive ganglion cells were counted and CFTR-positive ratios (number of CFTR-positive cells/ number of NF-positive cells) were calculated for each ganglion. The average of these positive ratios was also calculated for all sampled ganglia in each subject.

\section{RESULTS}

\section{Morphology of Ganglia}

All cell types evaluated in this study were based on morphology with $H \& E$ staining and immunostaining. Ganglia from all sampled locations were similar in histological structure, consisting of ganglion cells, satellite cells, nerve fibers and connective tissue. Ganglion cells were round or spindle shaped with abundant cytoplasm, a sharply defined nucleus, and many had a large nucleolus. Numbers of spinal ganglion cells (Figure 1a) per square millimeter were much greater than that of sympathetic ganglia (Figure 1b). On NFimmunostained sections, ganglion cells and their dendrites were clearly demonstrated (Figure $1 \mathrm{j}, \mathrm{n}$ and $\mathrm{q}$ ). The longest diameter of ganglion cell bodies ranged from 20 to $60 \mu \mathrm{m}$ with fewer dendrites than neurons in central nervous system. In any one ganglion, ganglion cells differed in size, and this variation was much more obvious in spinal ganglia. Cells in celiac ganglia were larger than those in the other ganglia of a given patient. Ganglion cells were surrounded by satellite cells that were intermingled with nerve fibers. The density of nerve fibers in spinal ganglia was less than that in sympathetic ganglia.

\section{Expression and Distribution of CFTR in Human Spinal and Sympathetic Ganglia by IHC}

Positive CFTR immunoreactivity was found in both human spinal and sympathetic ganglion cells. The specificity of CFTR antibody was confirmed by the antigen neutralization technique and the results are shown in Figure 1e-g. In the negative control, in which primary antibodies were substituted by PBS, no positive signal was found (Figure 1i and $\mathrm{m})$. Consecutive sections immunostained with NF and CFTR antibodies showed that ganglion cells, but not other cell types, were CFTR positive (Figure 1i-k and $\mathrm{m}-\mathrm{o}$ ). In general, ganglion cell CFTR staining included strongly positive clumpy focal membranous stain and multifocal grain-like diffusely distributed cytoplasmic reactivity that was slightly less intense than the membranous stain. Satellite cells, identified by morphology, were uniformly negative. In stomach mucosa, used as the positive control, CFTR was distributed mainly in the apical cytoplasm of glandular epithelial cells, and the positive signals in fundic glands were much stronger than those in surface mucosa cells (Figure 1c).

\section{Co-expression and Co-distribution of NF and CFTR by Destain and Restain Technique and Double-Staining Immunofluorescence}

The destain and restain technique using CFTR and NF antibodies was employed to determine whether CFTR-positive cells were ganglion cells. Figure 1 ( $\mathrm{q}$ and $\mathrm{r}$ ) shows positive destain and restain signals indicating that CFTR-positive cells were in fact NF-positive ganglion cells. Satellite cells, judged by morphology and IHC, were uniformly negative.

Co-expression of NF and CFTR and their distribution were further confirmed with double-staining immunofluorescence (Figure 2). All CFTR cells were also positive for NF. The CFTR-positive signals were distributed in the cytoplasm and membrane of ganglion cells, identical to that shown with IHC. The dendrites of these CFTR-positive cells were negative. There was no cross-reactivity between the immunostaining of the first and the second antigens.

\section{Numbers of CFTR-Positive Cells in Human Spinal and Sympathetic Ganglia}

Numbers of positive cells and ratios of CFTR-containing ganglion cells among all spinal and sympathetic ganglia were calculated as described in the Materials and methods. Results are shown in Table 2. Most ganglion cells were CFTR positive with an average positive ratio of $90.6 \%$ for the seven patients.

\section{Qualitative and Quantitative Analyses of CFTR mRNA in Human Spinal and Sympathetic Ganglion Cells}

The amplified products of nested RT-PCR were analyzed with agarose gel electrophoresis. Product analysis of human spinal and sympathetic ganglia and ileal mucosa from one patient are shown in Figure 3. From the total RNA extracted from human spinal and sympathetic ganglia, a final product of $328 \mathrm{bp}$ was amplified for all seven subjects. 

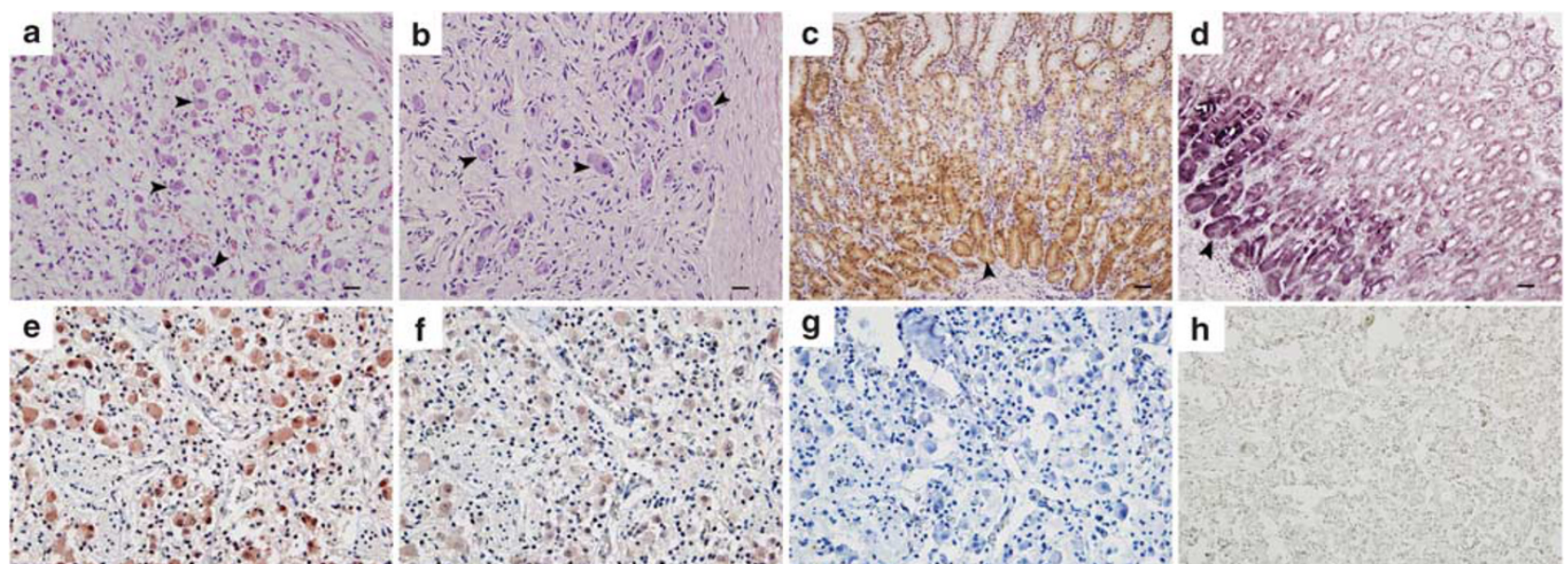

h
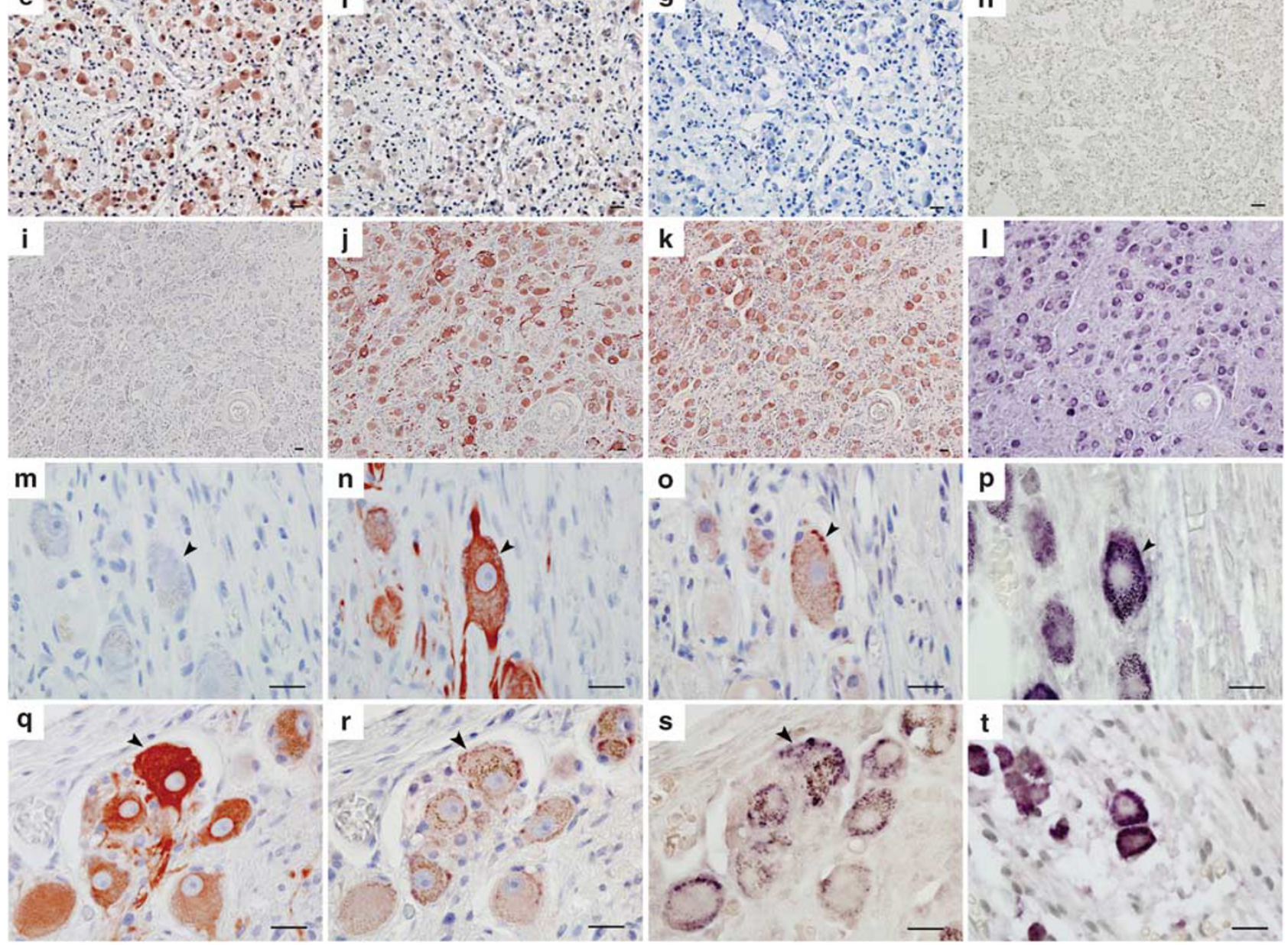

Figure 1 Expression and localization of CFTR in human spinal and sympathetic ganglia. (a, b) Spinal ganglion (a) and stellate ganglion (b) were stained by H\&E. Some ganglion cells are indicated with black arrows. (c) CFTR expression and location are shown by IHC in stomach tissue as a positive control. Grainlike positive signals of CFTR protein, indicated with black arrow, are brown in color with DAB, and disperse in the apical cytoplasm. (d) CFTR mRNA detection in stomach with ISH. CFTR mRNA is purple with NBT/BCIP indicated with black arrow. (e-g) Antigen neutralization test was performed on three consecutive sections to verify the specificity of CFTR antibody. CFTR protein $(0.004,0.04$ and $0.4 \mathrm{ng})$ was added to neutralize the antibody before the solution mixtures were applied onto the three sections. The positive color densities, shown red with AEC, decreased sequentially as the antigen concentrations increased, establishing the specificity of the CFTR antibody. (h) Negative control of ganglion is demonstrated with ISH, in which the sense probes were used, and no positive signal was found. (i-I) Consecutive sections with negative controls (i), NF positive (j) and CFTR positive (k) in IHC with AEC as the chromogenic agent. (I) Shows NBT/BCIP staining by ISH to detect CFTR mRNA. Most ganglion cells were CFTR positive. (m-p) These four photographs are from consecutive sections at higher magnification, and the same ganglion cell found in all four tissue sections is indicated with black arrows. (m), Negative control; (n), NF positive and (o), CFTR positive in IHC colored by AEC. In (n), ganglion cells are marked with NF immunostaining, in which cell bodies and dendrites are clearly visible. (o) CFTR protein is present in cytoplasm of ganglion cells both as microgranules and clumpy focal on the cell membrane. (p) Positive signals for CFTR mRNA are microgranular and are distributed in cytoplasm as shown by ISH. The location of CFTR mRNA is identical to CFTR antigen demonstrated by IHC as shown in (o). (q) Ganglion cells were marked with NF immunostaining, in which cell bodies and dendrites were clearly visible colored with AEC. (r) The same ganglion cells were also positive (red) for CFTR. CFTR was expressed in the cytoplasm with much stronger staining on cell membrane than other areas of the cells. (s) The consecutive section to $\mathbf{q}$ and $\mathbf{r}$, which was performed with ISH using CFTR antisense probes. The location of CFTR mRNA is identical to CFTR antigen demonstrated by IHC as shown in (r). The same ganglion cell is indicated with black arrows in (q-s). Brown lipofuscin microgranules distributed around the nucleus can be seen and this should not be confused with positive CFTR signals. (t) The positive signal of CFTR mRNA in human ganglion cells in a younger patient (4 years old) without lipofuscin. Scale bar $=20 \mu \mathrm{m}$. 

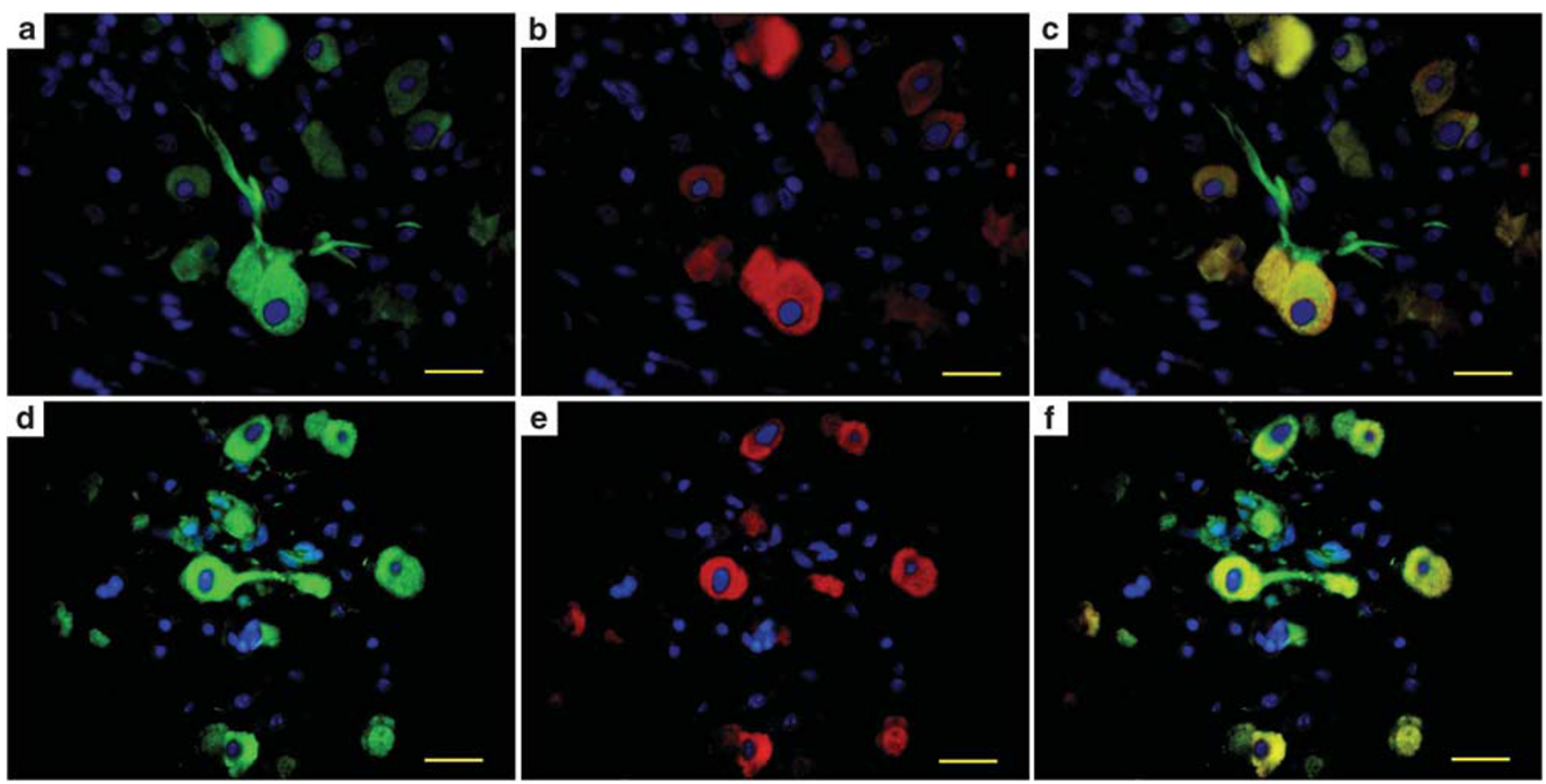

Figure 2 Double-staining immunofluorescence of NF and CFTR in a human spinal ganglion and a sympathetic ganglion. (a, d) Expression and distribution of NF as shown in FITC immunostaining (green). Positive signals are distributed in the ganglion cell bodies and dendrites. (b, e) Expression and distribution of CFTR as shown in TRITC immunostaining (red). Positive signals are distributed in the ganglion cell bodies. (c, f) Composite of NF-positive (green) and CFTR-positive signals (red). Co-expression of NF and CFTR is shown as a yellow signal. (a) and (b) show the same tissue section of human sympathetic ganglion, and (c) is the composite of these two photographs; (d) and (e) are the same tissue section of human spinal ganglion, and (f) is the composite. Scale bar $=20 \mu \mathrm{m}$.

Table 2 CFTR-positive ratio in human ganglia of seven subjects ((\%), CFTR-positive cells/NF-positive cells)

\begin{tabular}{lccccccc}
\hline Number & 1 & 2 & 3 & 4 & 5 & 6 & 7 \\
\hline C spinal ganglion & $(91.3) 42 / 46$ & $(90.3) 28 / 31$ & $(92.3) 36 / 39$ & $(90.2) 37 / 41$ & $(90.5) 38 / 42$ & $(94.3) 33 / 35$ & $(93.2) 41 / 44$ \\
Stellate ganglion & $(87.9) 51 / 58$ & $(94.9) 36 / 39$ & $(90.5) 38 / 42$ & $(88.4) 38 / 43$ & $(92.3) 36 / 39$ & $(92.7) 38 / 41$ & $(88.5) 46 / 52$ \\
$T_{5}$ sympathetic ganglia & $(94.7) 54 / 57$ & $(93.2) 41 / 44$ & $(91.1) 41 / 45$ & $(83.7) 36 / 43$ & $(92.9) 39 / 42$ & $(89.7) 35 / 39$ & $(92.7) 51 / 55$ \\
Celiac ganglia & $(90.2) 37 / 42$ & $(86.8) 33 / 38$ & $(87.2) 34 / 39$ & $(89.5) 34 / 38$ & $(84.6) 33 / 39$ & $(91.4) 32 / 35$ & $(86.0) 37 / 43$ \\
Inferior mesenteric ganglion & $(95.9) 47 / 49$ & $(90.0) 27 / 30$ & $(87.8) 36 / 41$ & $(88.2) 30 / 34$ & $(94.9) 37 / 39$ & $(91.7) 33 / 36$ & $(92.5) 49 / 53$ \\
Total average & $(91.7) 231 / 252$ & $(90.7) 165 / 182$ & $(89.8) 185 / 206$ & $(87.9) 175 / 199$ & $(91.0) 183 / 201$ & $(91.9) 171 / 186$ & $(90.7) 224 / 247$
\end{tabular}

The overall average positive ratio of CFTR expression of all samples is $90.6 \%(1334 / 1473)$.

mRNA transcript levels of CFTR and NF-M in ganglia from different sites were analyzed by relative qPCR. In general, amounts of NF-M were constant in each ganglion, but were much higher than that of CFTR $(P<0.05)$. Although the CFTR mRNA levels in stellate ganglia were slightly higher than those in the ganglia of other sites, this difference was not statistically significant.

\section{CFTR mRNA Detection in Human Spinal and Sympathetic Ganglia by ISH}

In situ hybridization was performed on sections consecutive to those used for IHC. Positive ISH signals were found in cytoplasm of ganglion cells, and these signals were stronger toward the cell membrane as compared with other areas of cytoplasm (Figure 1l, p, s and t). These ISH-positive cells were identical to those positive for IHC. No ISH-positive signal for CFTR mRNA was detected in satellite cells. In stomach mucosa, used as the positive control, the CFTRpositive signals were distributed mainly in the cytoplasm (Figure 1d) with a pattern similar to that seen in IHC (Figure 1c). In the negative control, no positive signal was found (Figure 1h).

\section{DISCUSSION}

This is the first report of CFTR expression in human spinal and sympathetic ganglion cells, and this work is a part of our 


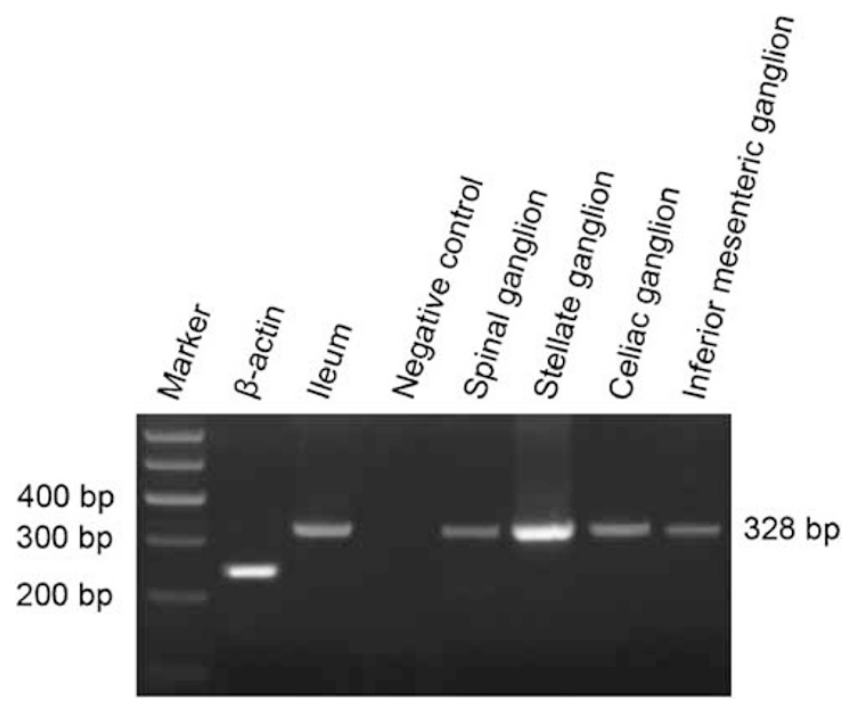

Figure 3 Agarose gel electrophoresis of nested RT-PCR amplification of mRNA extracted from human spinal and sympathetic ganglia. A light band of the predicted product of $328 \mathrm{bp}$ was observed in the spinal ganglion, stellate ganglion, celiac ganglion and inferior mesenteric ganglion from the same patient. The molecular weight was the same as that of the positive control. As a negative control, DEPC-treated water in place of RNA was used as the template and no resultant band was visible.

ongoing research wherein we also just reported the presence of CFTR in ganglion cells of rat hearts. ${ }^{30}$ This finding is likely to have significance for the study of $\mathrm{CF}$ and in understanding the function of this important protein.

Cystic fibrosis transmembrane conductance regulator protein was detected in the cytoplasm and plasma membrane of most ( $>90 \%)$ human spinal and sympathetic ganglion cells. We are currently studying CFTR expression in neurons of human spinal cord and brain. CFTR appears to be abundant in these sites as well. The presence of CFTR is indeed very widespread, if not ubiquitous, in ganglia and neurons.

In this study, CFTR co-expression with NF was confirmed by the destain and restain technique and double-staining immunofluorescence. CFTR mRNA was detected in the cytoplasm of the same ganglion cells that were CFTR protein positive. Positive CFTR antigen signals were distributed in the cytoplasm and were stronger near the cell membrane. Distribution of positive signals of ISH was very similar to those of IHC. Membrane expression in ganglion cells suggests that CFTR protein may have a channel function in these cells similar to that established for other cell types. In particular, the expression site was in concordance with its 'channel' function in epithelial cells.

Cystic fibrosis transmembrane conductance regulator mRNA was amplified with nested RT-PCR and quantified with relative qPCR. Its presence showed no significant difference among ganglia of different sites indicating that CFTR was relatively constantly expressed in these ganglion cells.
With negative and positive controls and the antigen neutralization test, the specificity of our qualitative and quantitative results has been well established. The abundant presence and relatively constant expression in human spinal and sympathetic ganglion cells indicate that CFTR may be basic and important to the normal function of these cells.

Cystic fibrosis transmembrane conductance regulator expression and function in epithelial cells have been studied extensively. As a chloride channel, CFTR takes part in maintaining cell volume and normal function by regulating salt transport, ion concentrations and fluid flow. ${ }^{31,32}$ It is distributed in subcellular organelles and critical for membrane recycling involved in endo- and exocytosis. ${ }^{20,33}$ Mutation of CFTR in ganglion cells may result in cellular dysfunction that manifests as abnormalities of peripheral nervous system of CF as well.

\section{CFTR Expression in Spinal Ganglion Cells and Peripheral Nerve Dysfunction of Patients with CF}

Subclinical peripheral nerve dysfunction was reported in patients with $\mathrm{CF}^{3}$ In comparison with normal controls, electrical abnormalities in somatic sensory and motor nerves were detected in 15 (62\%) of 24 patients with CF; sensory conduction velocity decreased $29 \%$ in the median nerve and $25 \%$ in the sural nerve; the compound muscle action potential in the peroneal nerve was low in $17 \%$; the sensory nerve action potential was low in $17 \%$ of the sural nerve. ${ }^{3}$ In the present study we detected CFTR in spinal ganglion cells, and subsequent studies may shed more light on possible involvement of CFTR in electrical dysfunction of somatic sensory nerves in CF patients.

\section{CFTR Expression in Autonomic Ganglion Cells and Autonomic Derangements of Patients with CF}

Based on various neurotransmitters, the autonomic nerve fibers arising from sympathetic ganglion cells or parasympathetic ganglion cells are divided classically into $\alpha$-adrenergic, $\beta$-adrenergic, cholinergic and peptidergic nervous fibers. Some of the neurotransmitters and neuromodulators are colocalized. These nerves work together to stabilize the internal environment of the organism and to regulate various functions. Dysfunction of ganglion cells may affect multiple organs and result in functional changes. Autonomic derangement in patients with CF has been noted for many years. ${ }^{4}$

The autonomic $\alpha$-adrenergic responses were found abnormal in patients with CF. The pupil, a nonglandular autonomically innervated site, was investigated and the level and rate of papillary dilation response to darkness and painful stimuli was found decreased in patients with CF compared to age-matched healthy controls or patients with other chronic illnesses, suggesting a possible dysfunction of autonomic nervous system in CF patients. ${ }^{5,6}$ Moreover, to exogenous $\alpha$-adrenergic stimuli, the pupil of patients with CF dilated more sensitively than healthy controls, suggesting an 
exaggerated $\alpha$-adrenergic sensitivity that is significantly related to the severity of $\mathrm{CF}^{11}{ }^{1}$ It is evident that obligate heterozygotes (phenotypically normal parents of patients with $\mathrm{CF}$ ) are more $\alpha$-adrenergic sensitive than healthy controls and less than those of CF patients significantly. ${ }^{11}$

Cardiovascular responses in CF patients were aberrant as well. Cardiac arrest, profound electrocardiogram changes, premature atrial and ventricular contractions, and supraventricular tachycardia were detected in CF patients without aberrant conduction, suggesting intracardiac autonomic imbalances. $^{7,8}$ The blood pressure in patients with CF was found significantly lower than age-matched healthy controls. ${ }^{9}$ Responses of the blood pressure ${ }^{9}$ and the pulse ${ }^{10}$ to postural changes were much insensitive in CF. The cardiovascular system of patients with CF responses less sensitively to the $\beta$-adrenergic agonist than normal controls. ${ }^{11}$

Cholinergic responses are exaggerated in patients with CF. Sibinga and Barbero ${ }^{12}$ observed that night sweating volume and rate increased in afebrile children with CF much more than normal controls. It is frequent that the saliva of $\mathrm{CF}$ patients is nepheloid. This phenomenon can be induced in normal children by administration of cholinomimetics, and ganglion blockade can induce secretion of nonturbid saliva by children with $\mathrm{CF}$, indicating that autonomic ganglion is involved in abnormality of exocrine in $\mathrm{CF} .{ }^{13}$ Pupillary constriction response in darkness to carbamylcholine is more sensitive in CF patients than normal controls, and the obligate heterozygotes displayed mean sensitivity to the papillary constriction of carbamylcholine intermediate between the normal controls and the CF patients. ${ }^{11}$

The pathogenesis of autonomic aberrations in $\mathrm{CF}$ is complicated. It may be partially related to diabetes mellitus, hepatic nodularity, vitamin deficiencies and autoimmunology in $\mathrm{CF}^{34}$ Abnormalities in autonomic nervous system discussed above were not significantly correlated with atopy, pancreatic insufficiency or drug administration with $\mathrm{CF}$, and it is interesting to note that the adrenergic and cholinergic responses are mildly abnormal in asymptomatic obligate heterozygotes. ${ }^{11,35,36}$ In this study, CFTR, the causative gene was found being expressed abundantly in human ganglion cells and this may help to understand the pathophysiological derangements in autonomic nervous system and abnormal exocrine function in CF. In addition to metabolic, nutritional and immunological factors, ${ }^{34}$ CFTR dysfunction in ganglion cells may be involved in this disease.

In conclusion, our study demonstrated extensive and constant expression of CFTR in human spinal and sympathetic ganglia. This wide distribution in ganglia suggests that this protein may be important in maintaining normal structures and physiological functions of ganglion cells. Moreover, it may contribute to the pathogenesis and pathophysiological changes in autonomic nerve system of CF. Our findings call for further investigation of the functional and pathological significance of this molecule in the spinal and sympathetic ganglion cells in human.

\section{ACKNOWLEDGEMENTS}

We thank Fanghua Jia (Department of Human Anatomy, Weifang Medical University) for technical assistance, and Yi Jen Jiang and Dr Michael A McNutt for editing this article. This project was supported partially by grants from the National Natural Science Foundation of China (code 30570686), Project 111 (B07001) of Ministry of Education, and Li Fu Educational Foundation.

1. Riordan JR, Rommens JM, Kerem B, et al. Identification of the cystic fibrosis gene: cloning and characterization of complementary DNA. Science 1989;245:1066-1073.

2. Boat TF, Welsh MJ, Beaudet AL. Cystic fibrosis. In: Scriver CL, Sly WS, Valle D (eds). The Metabolic Basis of Inherited Disease. McGraw-Hill: New York, 1989, pp 2649-2680.

3. O'Riordan Jl, Hayes J, Fitzgerald MX, et al. Peripheral nerve dysfunction in adult patients with cystic fibrosis. Ir J Med Sci 1995;164:207-208.

4. Di Sant'Agnese PA, Davis PB. Research in cystic fibrosis. N Engl J Med 1976;295:481-485, 534-541, 597-602.

5. Rubin LS, Barbero GJ, Chernick WS, et al. Pupillary reactivity as a measure of autonomic balance in cystic fibrosis. J Pediatr 1963;63:1120-1129.

6. Rubin LS, Barbero GJ, Chernick WS. Pupillary dysfunction as a concomitant of cystic fibrosis. Pediatrics 1966;38:865-873.

7. Zebrak J, Skuza B, Pogorzelski A, et al. Partial CFTR genotyping and characterisation of cystic fibrosis patients with myocardial fibrosis and necrosis. Clin Genet 2000;57:56-60.

8. Sullivan MM, Moss RB, Hindi RD, et al. Supraventricular tachycardia in patients with cystic fibrosis. Chest 1986;90:239-242.

9. Lieberman J, Rodbard S. Low blood pressure in young adults with cystic fibrosis: an effect of chronic salt loss in sweat? Ann Intern Med 1975;82:806-808.

10. Lake $C R$, Davis PB, Ziegler $M$, et al. Electrolytes and norepinephrine levels in blood of patients with cystic fibrosis. Clin Chim Acta 1979;92:141-146.

11. Davis $\mathrm{PB}$, Shelhamer JR, Kaliner M. Abnormal adrenergic and cholinergic sensitivity in cystic fibrosis. N Engl J Med 1980;302: 1453-1456.

12. Sibinga MS, Barbero GJ. Studies in the physiology of sweating in cystic fibrosis. II. Elevated night sweating rates. Arch Dis Child 1961;36:537-539.

13. Chernick WS, Barbero GJ. Reversal of submaxillary salivary alterations in cystic fibrosis by guanethidine. Bibl Paediatr 1967;86:125-134.

14. Trezise $A E$, Buchwald M. In vivo cell-specific expression of the cystic fibrosis transmembrane conductance regulator. Nature 1991;353: 434-437.

15. O'Riordan CR, Erickson A, Bear C, et al. Purification and characterization of recombinant cystic fibrosis transmembrane conductance regulator from Chinese hamster ovary and insect cells. J Biol Chem 1995;270:17033-17043.

16. Tizzano EF, Silver MM, Chitayat D, et al. Differential cellular expression of cystic fibrosis transmembrane regulator in human reproductive tissues. Clues for the infertility in patients with cystic fibrosis. Am J Pathol 1994;144:906-914.

17. Kogan I, Ramjeesingh M, Li C, et al. CFTR directly mediates nucleotideregulated glutathione flux. EMBO J 2003;22:1981-1989.

18. Smith JJ, Welsh MJ. CAMP stimulates bicarbonate secretion across normal, but not cystic fibrosis airway epithelia. J Clin Invest 1992;89:1148-1153.

19. Lukacs GL, Chang XB, Kartner N, et al. The cystic fibrosis transmembrane regulator is present and functional in endosomes. Role as a determinant of endosomal pH. J Biol Chem 1992;267:1456814572.

20. Hasegawa $\mathrm{H}$, Skach $\mathrm{W}$, Baker $\mathrm{O}$, et al. A multifunctional aqueous channel formed by CFTR. Science 1992;258:1477-1479.

21. Chandy G, Grabe M, Moore HP, et al. Proton leak and CFTR in regulation of Golgi pH in respiratory epithelial cells. Am J Physiol Cell Physiol 2001;281:C908-C921.

22. Bradbury NA, Jilling $T$, Berta $G$, et al. Regulation of plasma membrane recycling by CFTR. Science 1992;256:530-532.

23. Bradbury NA. Intracellular CFTR: localization and function. Physiol Rev 1999;79:S175-S191. 
24. Johannesson $M$, Bogdanovic N, Nordqvist AC, et al. Cystic fibrosis mRNA expression in rat brain: cerebral cortex and medial preoptic area. Neuroreport 1997;8:535-539.

25. Mulberg AE, Weyler RT, Altschuler SM, et al. Cystic fibrosis transmembrane conductance regulator expression in human hypothalamus. Neuroreport 1998;9:141-144.

26. Richard L, Drake WV, Adam WM. Gray's Anatomy for Students, vol. 1. Peking University Medical Press: Beijing, 2005.

27. Yamashita S. Heat-induced antigen retrieval: mechanisms and application to histochemistry. Prog Histochem Cytochem 2007;41: 141-200.

28. Gu J, de Mey J, Moeremans M, et al. Sequential use of the PAP and immunogold staining method for the light microscopical double staining of tissue antigens. Regul Pept 1981;1:365-374.

29. Deng R, Lu M, Korteweg C, et al. Distinctly different expression of cytokines and chemokines in the lungs of two H5N1 avian influenza patients. J Pathol 2008;216:328-336.
30. Pan P, Guo Y, Gu J. Expression of cystic fibrosis transmembrane conductance regulator in ganglion cells of the hearts. Neurosci Lett 2008;441:35-38.

31. Egan $M$, Flotte $T$, Afione $S$, et al. Defective regulation of outwardly rectifying $\mathrm{Cl}^{-}$channels by protein kinase $A$ corrected by insertion of CFTR. Nature 1992;358:581-584.

32. Sheppard DN, Welsh MJ. Structure and function of the CFTR chloride channel. Physiol Rev 1999;79:S23-S45.

33. Mulberg AE, Wiedner EB, Bao X, et al. Cystic fibrosis transmembrane conductance regulator protein expression in brain. Neuroreport 1994;5:1684-1688.

34. Mirakhur A, Walshaw MJ. Autonomic dysfunction in cystic fibrosis. J R Soc Med 2003;96(Suppl 43):11-17.

35. Davis PB, Byard PJ. Heterozygotes for cystic fibrosis: models for study of airway and autonomic reactivity. J Appl Physiol 1989;66:2124-2128.

36. Davis PB. Autonomic and airway reactivity in obligate heterozygotes for cystic fibrosis. Am Rev Respir Dis 1984;129:911-914. 